\title{
BMJ Open Influence of severe knee pain, meniscus surgery and knee arthroplasty on physical ability: an observational study of 114949 adults in the CONSTANCES cohort
}

\author{
Remi Valter, ${ }^{1,2,3}$ Diane Godeau, ${ }^{4,5}$ Annette Leclerc, ${ }^{6}$ Alexis Descatha (D) , 2,3,6,7 \\ Marc Fadel (i) 1,2,3
}

To cite: Valter R, Godeau D, Leclerc A, et al. Influence of severe knee pain, meniscus surgery and knee arthroplasty on physical ability: an observational study of 114949 adults in the CONSTANCES cohort. BMJ Open 2019;9:e031549. doi:10.1136/ bmjopen-2019-031549

- Prepublication history for this paper is available online. To view these files, please visit the journal online (http://dx.doi.org/ 10.1136bmjopen-2019-031549)

Received 08 May 2019 Revised 07 September 2019 Accepted 23 September 2019

Check for updates

(c) Author(s) (or their employer(s)) 2019. Re-use permitted under CC BY-NC. No commercial re-use. See rights and permissions. Published by BMJ.

For numbered affiliations see end of article.

Correspondence to

Dr Marc Fadel;

marc.fadel@ens.uvsq.fr

\section{ABSTRACT}

Background The knee is one of the major sites of musculoskeletal pain, yet few large-scale studies have evaluated the impact of knee disorders on physical limitations. Our objective was to describe this impact in a large-scale population study.

Methods We included subjects of working age from the CONSTANCES cohort, from its inception. Four groups were distinguished according to their medical history: whether they had knee arthroplasty (KA), meniscus surgery, severe knee pain, or none of these. Outcomes assessed for physical limitations were self-reported limitations in the last 6 months due to health problems, limitation on carrying $5 \mathrm{~kg}$ on $10 \mathrm{~m}$ and a 3-metre length rapid gait speed test (for participants aged $>45$ ). Associations between knee groups and patients' characteristics and physical limitations were analysed using logistic regression. Robust associations were deemed relevant if their ORs were higher than 2 and their $p$ value lower than 0.0001 .

Results Of the 114949 individuals, 99052 (86.2\%) were in the 'no pain and no surgery' group, $14740(12.8 \%)$ were in the severe knee pain group, $1019(0.89 \%)$ had meniscus surgery and $138(0.12 \%)$ had KA. Severe knee pain and KA groups showed a similar profile (they were less at work, reported more deterioration in their health and had more limitations).

Conclusion Almost $14 \%$ of the sample had knee disorders. Subjects reporting severe knee pain or who had KA reported more important physical limitations then subjects who reported neither severe knee pain nor knee surgery.

\section{INTRODUCTION}

The knee is one of the main sites of musculoskeletal disorders or diseases which often lead to physical limitations, pain and decreased quality of life. ${ }^{1}$ Knee disorders are common among the general population and keep increasing ${ }^{2}$ but few large scale studies addressed the issue of physical limitations
Strengths and limitation of the study

This study presents data on physical limitations of a large population of almost 115000 subjects.

- Only strong associations $(0 R>2$ or $<0.5$ with a p value $<0.0001$ ) are considered.

- Different knee conditions are analysed: severe knee pain, knee arthroplasty and meniscus surgery.

- Physical limitations are assessed by two selfreported outcomes (self-reported limitations in the last 6 months due to health problems and limitation on carrying $5 \mathrm{~kg}$ on $10 \mathrm{~m}$, and a clinical outcome (a 3-metre length rapid gait speed test).

- This study is cross-sectional and no multivariate analyses are performed, making it impossible to conclude on causality or consequences.

caused by knee disorders among the working population.

There are several treatments that are effective for relieving pain, including analgesics and sometimes surgery. Despite these treatments, the challenge is to identify patients who are significantly affected in their everyday life, whether at work or not. Indeed, when medically possible, preserving adequate physical function is essential both for patients who undergo surgery and those who do not. Meniscus surgery is often associated with good clinical outcomes (including recurrence of symptoms) $)^{3}$, as well as knee arthroplasty (KA), ${ }^{4}$ but those studies often focussed on selected population. Knee pain and its impact on physical ability are more heterogeneous and depend on the aetiology. ${ }^{5}$

The purpose of this study was to describe physical limitations associated with different knee conditions in the working population. For this, physical limitations of almost 115000 subjects recruited from the cohort 
CONSTANCES ("Consultants des Centres d'Examens de Santé") were analysed according to four groups: KA, meniscus surgery, severe knee pain and none of these.

\section{METHODS}

\section{Population}

Our population came from the French cohort CONSTANCES which is a population-based epidemiological cohort created in 2012 in partnership with French National Health Insurance. ${ }^{6}$ Participants included in this cohort are randomly selected adults, aged between 18 and 69. Data are collected through a self-administered questionnaire and a health examination in affiliated healthscreening centres. Those older than 45 years old have an additional health clinical examination.

Our survey included 114949 participants from CONSTANCES, restraining the participant's age to the working population (ages 18-65). We stopped collecting the data from the inclusion questionnaire and examination report in February 2018. Data for surgery (meniscus and KA, from 2009 to 2017) were retrieved from the National Health administrative databases. Subjects who underwent surgery in the year of the survey or later were not included.

\section{Variables of interest}

From the questionnaire, we retrieved participants' sex (man or woman), age, divided into three categories: $<50$ ('young'), between 50-60 ('middle-age') and $>60$ ('senior') and body mass index (BMI) for three categories: normal or underweight (BMI $\left.<25 \mathrm{~kg} / \mathrm{m}^{2}\right)$, overweight $\left(B M I \geq 25 \mathrm{~kg} / \mathrm{m}^{2}\right)$ and obese $\left(B M I \geq 30 \mathrm{~kg} / \mathrm{m}^{2}\right.$ ). Occupational activities and level of education were categorised respectively as follows: currently working (yes or no), and less than secondary education or no education, secondary to bachelor, more than bachelor's degree.

Self-reported health was categorised into three classes: 1-3 (good), 4 and 5 (intermediate), 6-8 (severe).

Three variables were used as outcomes to assess physical limitations: self-reported limitations in the last 6 months due to health problems, limitation on carrying $5 \mathrm{~kg}$ on $10 \mathrm{~m}$ and a 3-metre length rapid gait speed.

Self-reported limitations in the last 6 months due to a health-related problem, and limitation on carrying $5 \mathrm{~kg}$ for $10 \mathrm{~m}$, were coded from the questionnaire as follows: no limitation, intermediate limitation and severe limitation. For those older than 45, a 3-metre length rapid gait speed test and hand grip test were assessed and coded according to tertiles.

Using the self-reported questionnaire and the National Health administrative database, subjects were divided into four distinct categories: (1) KA (revision included); (2) meniscus surgery (but no KA); (3) severe knee pain intensity $>5 / 10$ or pain for more than a month/year (and no surgery); (4) no pain or intermediate knee pain (control group), that is, intensity $\leq 5 / 10$ and pain for less than a month/year (and no surgery). In France a score $>5$ indicates severe complaints/disorders. ${ }^{7}$

The meniscus surgery group was initially chosen as a comparison group for $\mathrm{KA}$, as this is a lighter operation performed on a less symptomatic population. ${ }^{8}$ The hand grip test was described here as a physical testing not directly related to knee disorder, but indirectly related to comorbidities. $^{9}$

\section{Data analysis}

Univariate logistic regression was used to compare the groups with knee conditions versus the control group for each of the aforementioned variables. Age stratification was performed. Only strong associations ( $O R>2$ or $<0.5$ with a $\mathrm{p}$ value $<0.0001$ ) were considered. Analyses were performed using Statistical Analyses System V.9.4.

\section{Patient and public involvement}

This research was done without patient involvement. Patients were not invited to comment on the study design and were not consulted to develop patient relevant outcomes or interpret the results. Patients were not invited to contribute to the writing or editing of this document for readability or accuracy.

\section{RESULTS}

Of the 114949 individuals, $53630(46.7 \%)$ were men and $61319(53.3 \%)$ women. As reported in table 1, 99 $052(86.2 \%)$ were in the 'no pain and no surgery' group, $14740(12.8 \%)$ were in the severe knee pain group, 1019 $(0.89 \%)$ had meniscus surgery and $138(0.12 \%)$ had KA.

An exhaustive description is presented in table 1 as well as results for each age subgroups. Thresholds separating the first and third tertiles for the 3-metre length rapid gait speed test were respectively $1.48 \mathrm{~s}$ and $1.72 \mathrm{~s}$ and for the hand grip test $45.3 \mathrm{~kg}$ and $38.3 \mathrm{~kg}$ (descending order).

Severe knee pain and KA groups had more severe limitation than the no/moderate pain group. Figure 1 shows the percentage of severe limitations in each knee conditions groups. Associations were approximately the same in the young, middle-aged and senior subgroups except for some strata in the $<50$ subgroup, which had fewer participants, and occupational status ('currently at work') for which significant relations were no longer found in the senior subgroup.

The severe knee pain group has a profile of physical limitations closer to the KA group than the meniscus surgery group (figure 2), even though the KA group had higher associations.

ORs for limitations in the last 6 months (severe vs no limitations) in the severe knee pain, meniscus surgery and KA groups were respectively 6.76 (95\% CI, (6.47 to 7.07)), 2.49 (2.12 to 2.94) and 11.45 (7.52 to 17.44). Likewise, ORs for limitations on carrying $5 \mathrm{~kg}$ on $10 \mathrm{~m}$ (severe vs no limitations) in the severe knee pain, meniscus surgery and KA groups were respectively 7.35 (6.70 to 8.06), 3.04 (2.10 to 4.40 ) and 10.46 (5.59 to 19.57); ORs for the 


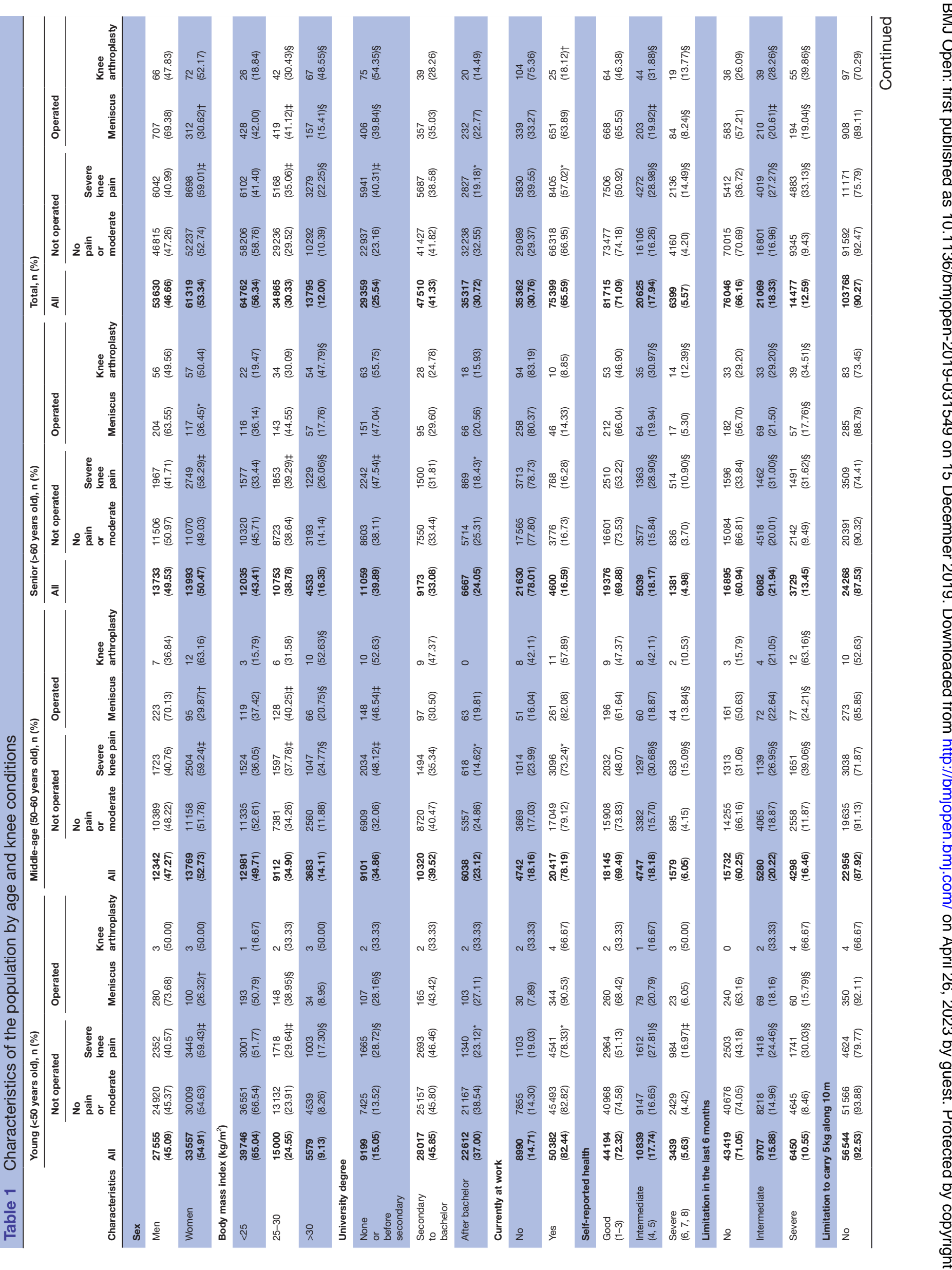




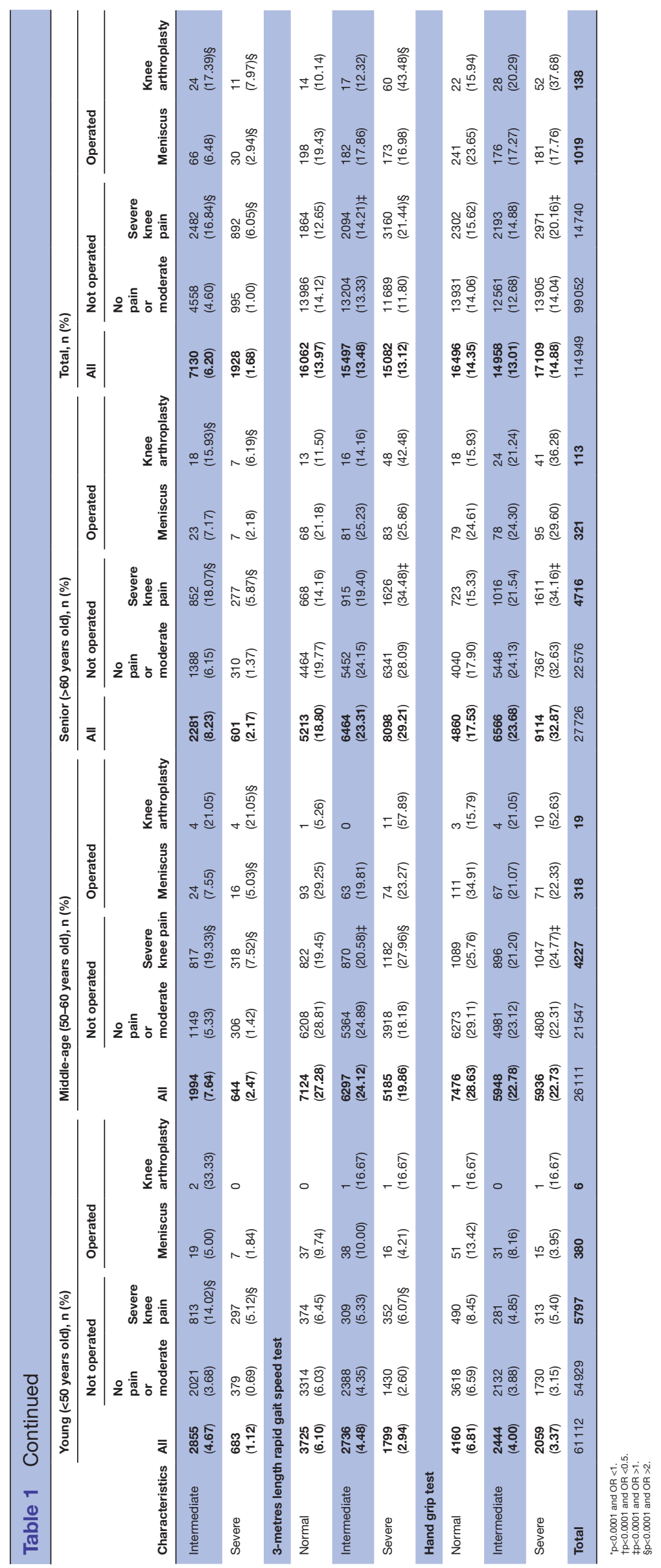




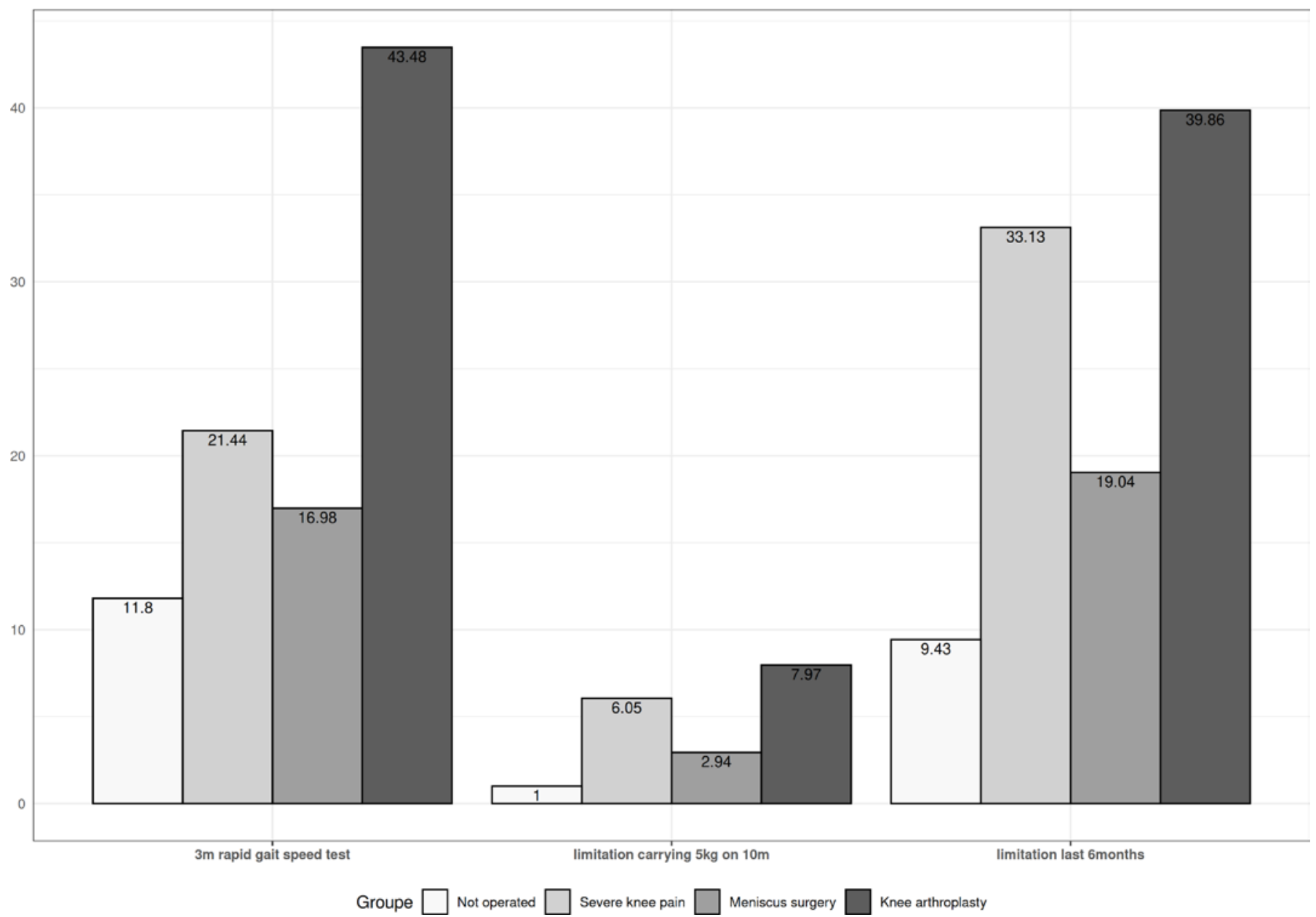

Figure 1 Percentage of severe physical limitation for each knee condition groups.

3-metres length rapid gait speed test (severely altered vs normal test) in the severe knee pain, meniscus surgery and KA groups were respectively 2.03 (1.91 to 2.16), 1.05 (0.85 to 1.28 ) and 5.13 (2.87 to 9.18 ).

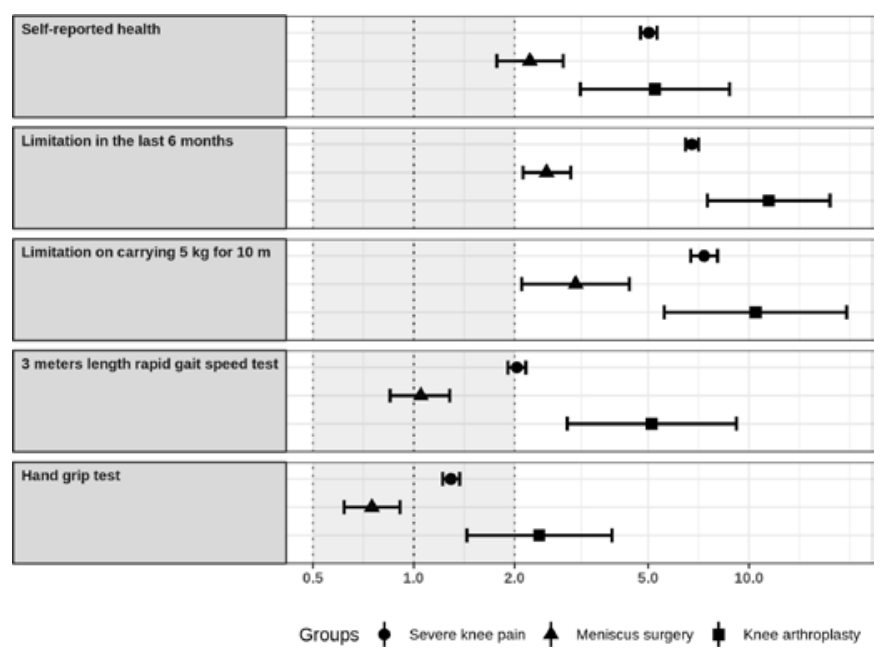

Figure 2 Forest plot showing associations (ORs) for each knee condition and severe physical limitations, on a logarithmic scale with base 10.

\section{DISCUSSION}

Participants who had severe knee pain or knee surgery reported more physical limitation than participants who had neither. To our knowledge, this is one of the only studies that provides an overview of knee disorders in a large general population-based sample that focusses on the working population. The detailed numbers allow clinicians to give information to their patients with knee disorders belonging to various age groups. Indeed, these numbers may help clinicians consider their patients' physical ability on a larger scale and compare them according to their knee conditions, while keeping in mind that participants without knee condition also reported physical limitation (figure 1). Disparities were observed regardless of age and are consistent with other studies. ${ }^{10}{ }^{11}$ We observed other associations, which are known to be associated with knee osteoarthritis: in the knee condition groups, there is a higher number of obese people, fewer people working and more people who had no secondary education. ${ }^{12}$

Similar association trends between the severe knee pain and KA groups suggest that patients suffering from severe knee pain might benefit from similar evaluations and follow-up regardless of their operational status. Indeed, 
practitioners may be less aware of the need to assess physical limitations for subjects with knee pain than for subjects who had KA.

With information available from a year at least after meniscus surgery or KA, and from 2009 to 2017, we have tried to obtain descriptions not too close and not too far from the surgery. Although pain after KA is complex, ${ }^{13}$ patients suffering from severe knee pain might be on the same continuum as patients suffering from chronic pain after KA. As shown in a systematic review, $8.0 \%$ to $26.5 \%$ had an unfavourable pain outcome after surgery, ${ }^{14}$ while other studies have shown that severe preoperative pain or long-lasting pain prior to surgery are risk factors for severe postoperative pain. ${ }^{15} 16$

This study has several limitations. Despite a very large number of participants, it was not possible to evaluate the young group for KA. Furthermore, this study is descriptive, without information on temporal trends for pain or surgery, and with no multivariable analyses. Thus, we cannot take into account confounding factors and study any causality or consequences. In addition, we have compared subjects who reported pain and who had surgery 3-9 years before the questionnaire. Some might have a long history of knee disorders, surgery at young age and have (or not) pain. We also did not consider many potential conditions relevant to knee or health problems (depression, trauma, static disorders). However, the large sample of an adult population, and the descriptive approach, makes us confident we can avoid over-interpretation.

In conclusion, this study provides a global view on limitations for some knee disorders in the general population across age groups. It also suggests that people suffering from knee conditions have higher physical physical limitations than the general population, including patient suffering from severe knee pain without recent knee surgery.

\section{Author affiliations}

${ }^{1}$ Occupational Health Unit, Poincaré University Hospital, AP-HP (Paris Hospital) UVSQ, Garches, France

${ }^{2}$ UMS 011, UMR-S 1168, Versailles St-Quentin Univ - Paris Saclay Univ, Versailles, France

${ }^{3}$ VIMA : Aging and chronic diseases. Epidemiological and public health approaches, U1168, Inserm, Villejuif, F-94807, île-de-France, France

${ }^{4}$ Occupational and Environmental Diseases Unit, AP-HP (Paris Hospital) Hôpital Avicenne, University hospital Paris Seine-Saint-Denis, Bobigny, F-93009, Île-deFrance, France

${ }^{5}$ Paris 13 University Sorbonne, Paris, Île-de-France, France

${ }^{6}$ UMS 011 Population-based Epidemiologic Cohorts Unit, Inserm, Villejuif, Île-deFrance, France

${ }^{7}$ Irset (Institut de recherche en santé, environnement et travail) - UMR_S1085, Univ Angers, CHU Angers, Univ Rennes, Inserm, Angers, F-49000, Pays de la Loire, France

Contributors RV, DG, AL, $A D$ and MF equally contributed to the analysis and the writing of the paper.

Funding This study was supported by IReSP, CapaciT project (Institute for research in public health, in French- http://www.iresp.net/). The CONSTANCES Cohort Study was supported and funded by the Caisse nationale d'assurance maladie (CNAM). The CONSTANCES Cohort Study is an 'Infrastructure nationale en Biologie et Santé' and benefits from a grant from ANR (ANR-11-INBS-0002) and from the Ministry of Research. CONSTANCES is also partly funded by MSD, AstraZeneca and Lundbeck.

Competing interests The authors have no relevant conflicts of interest. They are paid by their affiliations. Alexis Descatha has received fees from Elsevier Masson as editor-in-chief of the journal 'les archives des maladies professionnelles et de l'environnement'.

Patient consent for publication Not required.

Ethics approval Authorisation from the appropriate ethics committee was obtained ('Commission nationale de l'informatique et des libertés' n 910486 , 'Comité consultatif sur le traitement de l'information en matière de recherche' $n^{\circ}$ 10.628). The study is in compliance with the Helsinki Declaration.

Provenance and peer review Not commissioned; externally peer reviewed.

Data availability statement The data of the CONSTANCES cohort are protected by our national regulatory agency ("Commission nationale de l'informatique et des libertés", n910486). However, the CONSTANCES cohort is "an open epidemiological laboratory" and access to study protocols and data is available on request (https://www.constances.fr/conduct-project-ongoing.php).

Open access This is an open access article distributed in accordance with the Creative Commons Attribution Non Commercial (CC BY-NC 4.0) license, which permits others to distribute, remix, adapt, build upon this work non-commercially, and license their derivative works on different terms, provided the original work is properly cited, appropriate credit is given, any changes made indicated, and the use is non-commercial. See: http://creativecommons.org/licenses/by-nc/4.0/.

\section{ORCID iDs}

Alexis Descatha http://orcid.org/0000-0001-6028-3186

Marc Fadel http://orcid.org/0000-0002-1554-0021

\section{REFERENCES}

1 Cross M, Smith E, Hoy D, et al. The global burden of hip and knee osteoarthritis: estimates from the global burden of disease 2010 study. Ann Rheum Dis 2014;73:1323-30.

2 Nguyen U-SDT, Zhang Y, Zhu Y, et al. Increasing prevalence of knee pain and symptomatic knee osteoarthritis: survey and cohort data. Ann Intern Med 2011;155:725-32.

3 O'Donnell K, Freedman KB, Tjoumakaris FP. Rehabilitation protocols after isolated meniscal repair: a systematic review. Am J Sports Med 2017;45:1687-97.

4 Kane RL, Saleh KJ, Wilt TJ, et al. The functional outcomes of total knee arthroplasty. J Bone Joint Surg Am 2005;87:1719-24.

5 Jones BQ, Covey CJ, Sineath MH. Nonsurgical management of knee pain in adults. Am Fam Physician 2015;92:875-83.

6 Zins M, Goldberg M, CONSTANCES team. The French CONSTANCES population-based cohort: design, inclusion and follow-up. Eur J Epidemiol 2015;30:1317-28.

7 Hagberg M, Violante FS, Bonfiglioli R, et al. Prevention of musculoskeletal disorders in workers: classification and health surveillance - statements of the scientific Committee on musculoskeletal disorders of the International Commission on occupational health. BMC Musculoskelet Disord 2012;13:109.

8 Lamplot JD, Brophy $\mathrm{RH}$. The role for arthroscopic partial meniscectomy in knees with degenerative changes. Bone Joint $J$ 2016;98-B:934-8.

9 Celis-Morales CA, Welsh P, Lyall DM, et al. Associations of grip strength with cardiovascular, respiratory, and cancer outcomes and all cause mortality: prospective cohort study of half a million UK Biobank participants. BMJ 2018;361:k1651.

10 Arnold JB, Walters JL, Ferrar KE. Does physical activity increase after total hip or knee arthroplasty for osteoarthritis? A systematic review. J Orthop Sports Phys Ther 2016;46:431-42.

11 Nguyen U-SDT, Ayers DC, Li W, et al. Preoperative pain and function: profiles of patients selected for total knee arthroplasty. J Arthroplasty 2016;31:2402-7.

12 Blagojevic M, Jinks C, Jeffery A, et al. Risk factors for onset of osteoarthritis of the knee in older adults: a systematic review and meta-analysis. Osteoarthritis Cartilage 2010;18:24-33.

13 Grosu I, Lavand'homme P, Thienpont E. Pain after knee arthroplasty: an unresolved issue. Knee Surg Sports Traumatol Arthrosc Off J ESSKA 2014;22:1744-58.

14 Beswick AD, Wylde V, Gooberman-Hill R, et al. What proportion of patients report long-term pain after total hip or knee replacement for osteoarthritis? A systematic review of prospective studies in unselected patients. BMJ Open 2012;2:e000435. 
15 Puolakka PAE, Rorarius MGF, Roviola M, et al. Persistent pain following knee arthroplasty. Eur J Anaesthesiol 2010;27:455-60.
16 Lewis GN, Rice DA, McNair PJ, et al. Predictors of persistent pain after total knee arthroplasty: a systematic review and meta-analysis. Br J Anaesth 2015;114:551-61. 